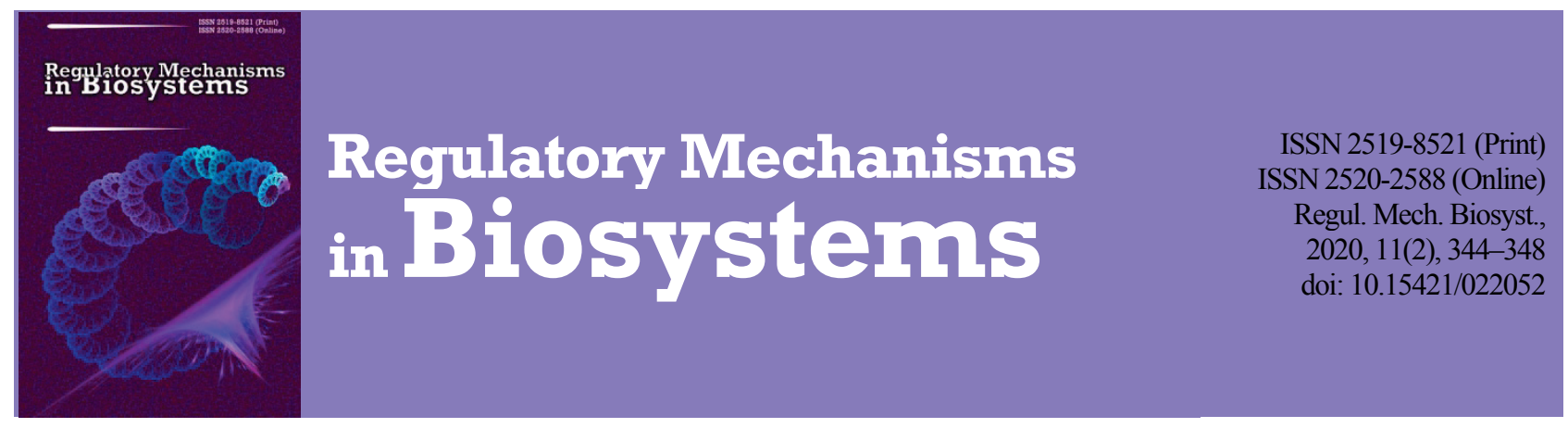

\title{
The impact of certain flavourings and preservatives on the survivability of eggs of Ascaris suum and Trichuris suis
}

\author{
O. O. Boyko*, V. V. Brygadyrenko*,** \\ *Dnipro State Agrarian and Economic University, Dnipro, Ukraine \\ **Oles Honchar Dnipro National University, Dnipro, Ukraine
}

Article info

Received 02.05.2020

Received in revised form 26.05 .2020

Accepted 28.05.2020

Dnipro State Agrarian and Economic University, S. Efremov st., 25, Dnipro, 49600, Ukraine. Tel: +38-099-405-51-98, E-mail: boikoalexandra1982@gmail.com

Oles Honchar Dnipro National University Gagarin Ave., 72, Dnipro, 49010, Ukraine. Tel.: +38-050-939-07-88.

E-mail:brigad@ua.fm

\begin{abstract}
Boyko, O. O., \& Brygadyrenko, V. V. (2020). The impact of certain flavourings and preservatives on the survivability of eggs of Ascaris suum and Trichuris suis. Regulatory Mechanisms in Biosystems, 11(2), $344-348$. doi:10.15421/022052
\end{abstract}

The article describes a laboratory study of nematocidal properties of flavourings with antibacterial effect against Ascaris suum (Goeze, 1782) and Trichuris suis Schrank, 1788. In the experiments, eight concentrations of food additives with antibacterial properties were used: cinnamaldehyde, benzoic acid, formic acid, linalool, citral, $\beta$-ionone. Minimum $\mathrm{LC}_{50}$ value for eggs of $A$. suum was observed while using cinnamaldehyde and benzoic acid $-1.62 \pm 0.37 \%$ and $1.69 \pm 0.14 \%$, and for eggs of T. suis $-0.57 \pm 0.03 \%$ and $1.80 \pm 0.11 \%$ respectively. The lowest influence on the development of eggs of nematodes of pigs' A. suum and T. suis was exerted by formic acid, linalool, citral and $\beta$-ionone. In eggs of $A$. suum and T. suis, larvae formed in 21 and 50 days even during exposure to $3 \%$ emulsions of these substances. The strongest negative impact on the eggs of parasitic nematodes was displayed by cinnamaldehyde flavouring. Further study on nematocidal properties of flavourings, as well as their mixtures, would contribute to the development of preparations which would have a strong effect on eggs and larvae of nematodes of animals and humans.

Keywords: nematodes of pigs; flavourings; preservatives; survivability of eggs.

\section{Introduction}

Two of the commonest helminthiases of swine around the globe are ascariasis and trichuriasis. The pathogens of these parasitic diseases cause economic damage to pig farming (Lindgren et al., 2019; Nwafor et al., 2019; Zheng et al., 2020). Today, most farmers use synthetic broad-spectrum anthelmintic preparations against ascariasis and trichuriasis of pigs, though some of them have notable side effects (Jakobsen et al., 2019; Vandekerckhove et al., 2019). At the same time, repeated infection poses a threat of development of nematodes' resistance to antiparasitic preparations (Ceballos et al., 2019; de Oliveira et al., 2019; Palma et al., 2020). Therefore, alternative veterinary and medical preparations with anthelmintic activity are now being searched for all around the world (Boyko \& Brygadyrenko, 2019c; Palchykov et al., 2019).

Numerous studies have been published focusing on the ways of combating Ascaris suum (Goeze, 1782). Oh et al. (2016) evaluated the effect of several disinfecting preparations on embryogenic development of eggs of $A$. suum. According to the results of their experiment, 3.0\% cresol and $0.02 \%$ sodium hypochlorite can slow the development, but not inactivate the eggs of $A$. suum. During 6 weeks of the incubation, eggs of these nematodes still completed the embryonic development. Likewise povidone-iodine in 10\% solution killed no eggs even during $60 \mathrm{~min}$ exposure.

Zhao et al. (2017) determined the influence of medicamental treatment on embryonic development of eggs of A. suum. Eggs were taken from the mother of immature ascarids extracted from the intestine of pigs. Zhao et al. (2017) also determined effect of abamectin, doramectin, ivermectin, flubendazole on embryonic development of eggs of A. suum. The process of the formation of larvae in eggs of nematodes of pigs which received abamectin, doramectin, and ivermectin reliably did not differ from the control. Flubendazole inhibited the development of embryos of the worms: only in $6.3 \%$ of eggs did larvae develop. However, in vitro exposure of eggs extracted from the contents of the intestines of pigs which received no anthelmintic preparations had no significant effect on the development of larvae.

Quite often in the literature one can find mentions of the effect of plants or their tinctures on the development of eggs of A. suum. Anthelmintic in vitro activity of common chicory (Cichorium intybus L.) was studied by Williams et al. (2016). They confirmed that methanol extract of plant has significant anthelmintic effect against A. suum.

Fitri et al. (2019) performed an in vitro experiment for determining the influence of ground seeds of papaya on the development of embryos in eggs of $A$. suum. The results of their studies suggest decreased ability of the exposed eggs to form vital embryos, in contrast to the control group of eggs. Nyasinge et al. (2018) also studied the influence of the alcohol extracts of plants on A. suum. Extracts from the plant Paullinia pinnata L. of the Sapindaceae family displayed significant anthelmintic activity towards eggs of $A$. suum. The plant was found to contain saponins, alkaloids, flavonoids, tannins and triterpenoids. The results of these studies on the anthelmintic effect of alcohol extract of the plant on $\mathrm{A}$. suum indicate higher mortality of eggs compared with albendazole.

Similar experiments were conducted by Simalango et al. (2018) who studied in vitro anthelmintic effect of ethanol extract of seeds of Nigella sativa L. (Ranunculaceae) against eggs of $A$. summ: $\mathrm{LC}_{50}$ equaled $1.693 \%$.

Williams et al. (2016) studied in vitro anthelmintic properties of traditional medicinal plants of Africa and the Caribbean Basin. The authors performed screening of ethanol extracts from 29 medical plants against A. suum. Extracts from Clausena anisata (Willd.) Hook. f. ex Benth. (Rutaceae), Zanthoxylum zanthoxyloides (Lam.) Zepern. \& Timler (Rutaceae) and Punica granatum L. (Lythraceae) proved to be the most efficient against $A$. suum. The results of their studies demonstrated the possibility of using these plants as additional variants of the treatment of mammals suffering from nematodes. Sea et al. (2017) report in vitro anthelmin- 
tic activity of tincture of leaves of holy basil Ocimum sanctum L. (Lamiaceae) towards A. summ: $15 \%$ aqueous tincture exhibited $100 \%$ efficiency against eggs of $A$. suum during $36 \mathrm{~h}$ exposure. An alternative for treatment against parasitic diseases of agricultural animals may be flavourings and feed additives with antiparasitic activity. Studies in this sphere are becoming popular in modern veterinary medicine (Ullah et al., 2015; Boyko \& Brygadyrenko, 2016, 2018). Many additives have already undergone both in vivo and in vitro tests (Lee et al., 2008; Cheng et al., 2009; Na et al., 2011; Shen et al., 2012; Yi et al., 2016).

Currently, there are no data on the influence of these and other aromatic substances and preservatives on the process of embryonic development of eggs of A. suum and T. suis. $\mathrm{LD}_{50}$ of cinnamaldehyde $\left(\mathrm{C}_{9} \mathrm{H}_{8} \mathrm{O}\right)$ for rats, mice and guinea pigs orally was 2220,2225 and $1160 \mathrm{mg} / \mathrm{kg}$ respectively (Jenner et al., 1964). $\mathrm{LD}_{50}$ of benzoic acid $\left(\mathrm{C}_{6} \mathrm{H}_{5} \mathrm{COOH}\right)$ for laboratory animals (intravenous administration to rats) equaled $1700 \mathrm{mg} / \mathrm{kg}$, for cats $300 \mathrm{mg} / \mathrm{kg}$ (Bedford \& Clarke, 1972; Jakimowska, 1961). LD $_{50}$ of formic acid for laboratory animals equaled 700, 1100 and $4000 \mathrm{mg} / \mathrm{kg}$ for mice, rats and dogs respectively (Von Oettingen, 1960, Montgomery, 2000). $\mathrm{LD}_{50}$ of linalool $\left(\mathrm{C}_{10} \mathrm{H}_{18} \mathrm{O}\right)$ for laboratory rats orally was $2790 \mathrm{mg} / \mathrm{kg}$ (Jenner et al., 1964). $\mathrm{LD}_{50}$ of citral $\left(\mathrm{C}_{10} \mathrm{H}_{16} \mathrm{O}\right)$ for rats orally was $4960 \mathrm{mg} / \mathrm{kg}$, for $\beta$-ionone $\left(\mathrm{C}_{13} \mathrm{H}_{20} \mathrm{O}\right)$ was $4590 \mathrm{mg} / \mathrm{kg}$ (Jenner et al., 1964). These data suggest relatively good tolerance of mammals to these groups of flavourings. The objective of this article was to assess the effect of cinnamaldehyde, benzoic acid, formic acid, linalool, citral, $\beta$-ionone on the development of larvae in eggs of nematode pathogens of ascariasis and trichuriasis in pigs.

\section{Materials and methods}

In the experiment on ovicidal activity of flavourings, we used noninvasive eggs of two species of pig nematodes: Ascaris suum (Goeze, 1782) and Trichuris suis Schrank, 1788. Feces of pigs were collected from yards of private households in Dnipropetrovsk Oblast (Ukraine). Manure was surveyed for presence of eggs of nematodes using McMaster method (Zajac et al., 2011). Then, samples of feces were collected in which the quantity of eggs of one species of nematodes in one gram of feces was no less than 500. Samples (separately with eggs of A. suum and separately with $T$. suis) were accurately mixed and average samples were extracted.

Then, the eggs were rinsed. For this purpose, a fecal mass of $10 \mathrm{~g}$ was put into a glass cup, the sample was accurately stirred to uniform mass and $100 \mathrm{~mL}$ of water was added. The eggs were rinsed several times until pure sediment was obtained. Then, the formed sediment was centrifuged (1,500 rpm) for $2 \mathrm{~min}$. Supernatant fluid was removed. Sediment with eggs from centrifuged test tubes was put by $0.1 \mathrm{~mL}$ (on average by 10-20 eggs) into plastic tubes $(1.5 \mathrm{~mL}$ ). Then, $1 \mathrm{~mL}$ of solutions (or emulsions) of cinnamaldehyde, formic acid, linalool, citral, $\beta$-ionone, suspension of benzoic acid, and also distilled water (control) were added in eight-fold replication. All the reagents were manufactured by Hebei Qige Biotechnology Co., Ltd. (China), Pro Analysi (>99\% purity). Immature eggs were exposed to the tested emulsions and solutions in various concentrations $(0.1,0.5,0.6,0.7,0.8,0.9,1.0$ and $3.0 \%)$ for $24 \mathrm{~h}$. Then, eggs of nematodes were rinsed and covered with distilled water. Test tubes were put into a thermostat. The eggs were cultivated at a temperature of $28{ }^{\circ} \mathrm{C}$ : A. suum -21 days, $T$. suis -50 days. Ovicidal activity of the substances was expressed as a percentage of the amount of formed eggs (eggs with larvae inside). The statistical analysis of the results was performed through the set of Statistica 8.0 (StatSoft Inc., USA). The figures show the median, $25 \%$ and $75 \%$ quartiles, minimum and maximum values. LC50 is expressed as a $\%$ : average $(\mathrm{x}) \pm$ standard deviation $(\mathrm{SD})$.

\section{Results}

The experiment revealed that the eggs of $A$. suum were the most resistant to the studied substances. Formation of larvae was observed in more than $90 \%$ of eggs exposed to formic acid, linalool, citral and $\beta$-ionone in different concentrations (up to $3 \%$ ) with the exposure of $24 \mathrm{~h}$ (Fig. 1).
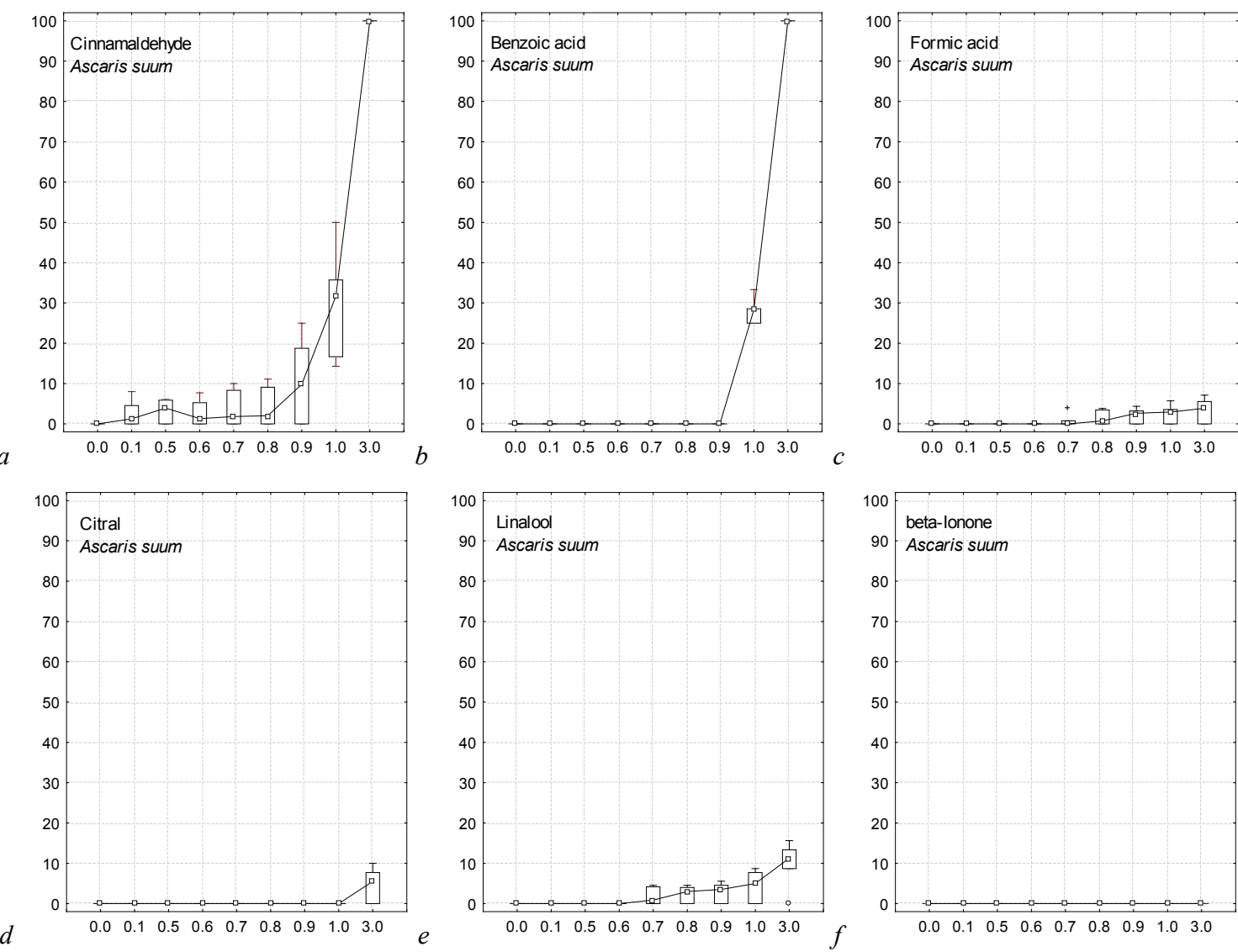

Fig. 1. The impact of certain flavourings and preservatives on vitality of eggs of Ascaris suum (Goeze, 1782): the ordinate axis indicates the percentage of living nematodes eggs in the course of the 24-hour experiment; the abscissa axis indicates the concentration of the solution's or emulsion's of active substance (\%); the small square in the centre corresponds to the median, the lower and upper edge of the large rectangle corresponds to first and third quartiles, respectively, the vertical segments, directed upward and downward from the rectangles, correspond to minimum and maximum values $(\mathrm{n}=8)$ 

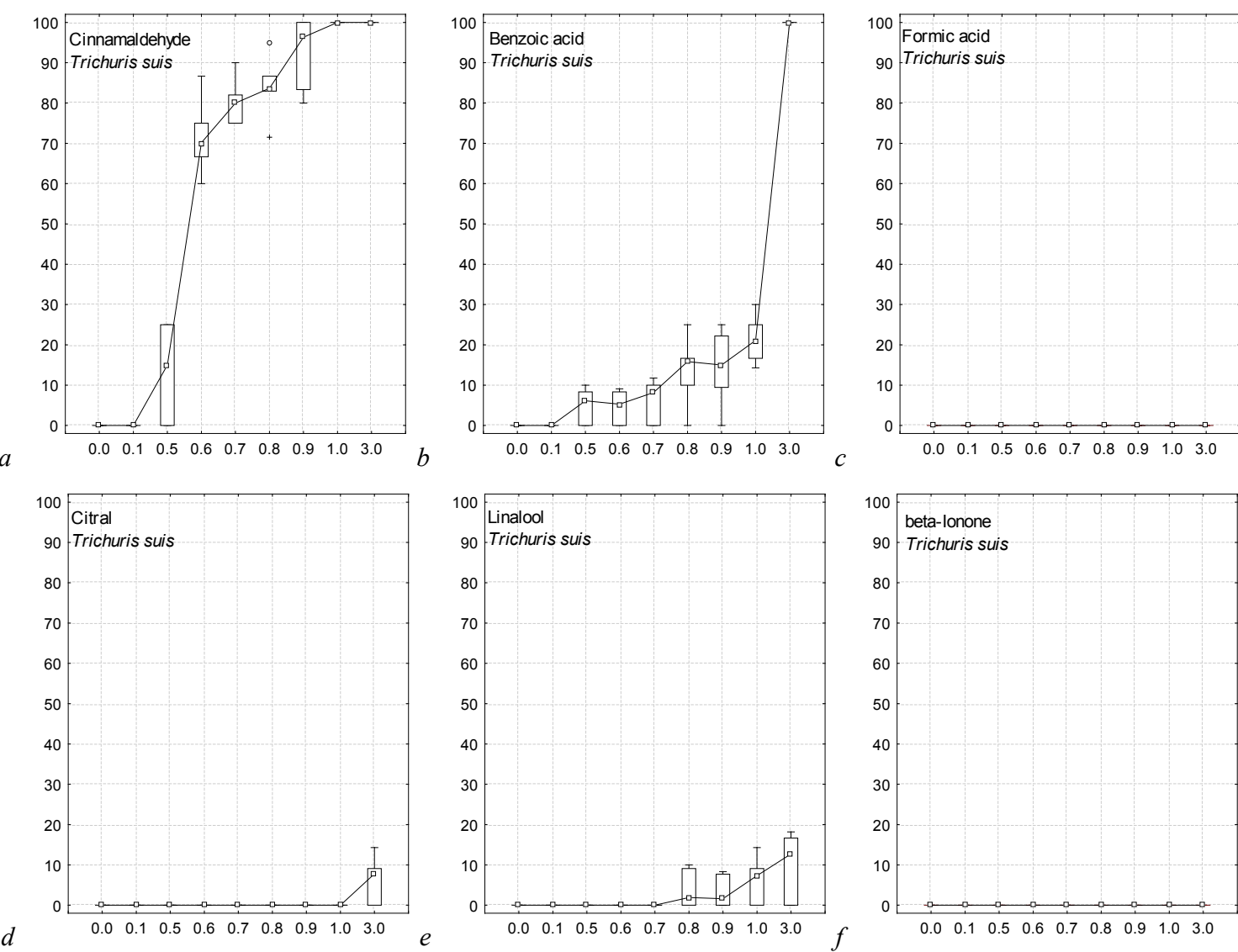

Fig. 2. The impact of certain flavourings and preservatives on vitality of eggs of Trichuris suis Schrank, 1788: the ordinate axis indicates the percentage of living nematodes eggs in the course of the 24-hour experiment; the abscissa axis indicates the concentration of the solution's or emulsion's of active substance (\%); the small square in the centre corresponds to the median, the lower and upper edge of the large rectangle corresponds to first and third quartiles, respectively, the vertical segments, directed upward and downward from the rectangles, correspond to minimum and maximum values $(\mathrm{n}=8)$

During $24 \mathrm{~h}$ exposure to cinnamaldehyde, mortality of $100 \%$ of noninvasive eggs (eggs with undeveloped larvae) was seen in the conditions of exposure to $3 \%$ emulsion. None of the remaining concentrations of cinnamaldehyde caused death to even $5 \%$ of eggs of $A$. suum over $24 \mathrm{~h}$.

Also, a significant influence on the development of eggs of $A$. suum was exerted by benzoic acid. Twenty-four hour exposure to $3 \%$ suspension of this acid caused $100 \%$ death to eggs of ascarids. During exposure of non-invasive eggs of $A$. suum to benzoic acid in less saturated concentrations, nematode larvae formed in over $70 \%$ of cases.

Eggs of A. suum were quite resistant to formic acid. Formation of larvae was recorded at $24 \mathrm{~h}$ exposure to different concentrations in more than $95 \%$ of eggs. Similar results were observed during the influence of citral and $\beta$-ionone.

Less resistant to the impact of the studied substances were the eggs of T. suis. A significant impact on the development of larvae in eggs was recorded during the exposure to cinnamaldehyde and benzoic acid (Fig. 2). During $24 \mathrm{~h}$ exposure to 3\% and 1\% emulsions of cinnamaldehyde, $100 \%$ death of eggs of T. suis was observed. The number of invasive eggs gradually increased with gradual decrease of concentration of this substance. A total of $85 \%$ of eggs remained vital during exposure to $0.5 \%$ cinnamaldehyde. This substance in $0.1 \%$ solution took no effect on the development of larvae in $100 \%$ of cases.

Benzoic acid showed a lower effect: during exposure to $3 \%$ suspension no larvae were seen to form in $100 \%$ of eggs. However, the effect of $1 \%$ benzoic acid differed from the effect of the previous substance in this concentration: in $80 \%$ of cases in eggs of $T$. suis we observed the formation of larvae. Less than $10 \%$ of embryos in eggs exposed to lower concentrations of this substance $(0.7,0.6,0.5$ and $0.1 \%)$ were observed to be dead. At the exposure of eggs of T. suis to formic acid, no effect was observed. Almost all the eggs formed larvae inside regardless of the concentration of this acid. Similar results were obtained also during the influence of $\beta$-ionone. Exposure of eggs of $T$. suis to $3 \%$ citral and linalool was accompanied by death of about $10 \%$ of eggs. The rest of the studied concentrations of these substances took no effect on the development of eggs in $100 \%$ of cases.

\section{Discussion}

The antimicrobial properties of cinnamaldehyde, benzoic acid, formic acid, linalool, citral, $\beta$-ionone are actively studied (Saddiq \& Khayyat, 2010; Manu, 2016; Ding, 2017; Brütsch et al., 2017; Alborzi et al., 2018; Durgadevi et al., 2019; Ren et al., 2020). Manu (2016) assessed the antimicrobial efficiency of cinnamaldehyde and geraniol against Escherichia coli $\mathrm{O} 157: \mathrm{H} 7$ and Salmonella enterica: cinnamaldehyde $(2.0 \mu \mathrm{L} / \mathrm{mL})$ exerted the highest bactericidal effect against both pathogenic bacteria. This author has also determined that cinnamaldehyde has a great potential for the control of the growth of pathogenic bacteria of food origin in cooled fruits and vegetable juices. Brütsch et al. (2017) studied the antimicrobial properties of formic acid produced by wood ants and determined that this acid can also increase antimicrobial properties of treecollected resin used by ants. Ren et al. (2020) determined the potential of formic acid and monolaurin as an alternative to antibiotics in the diet of piglets infected by ETEC (enterotoxigenic Escherichia coli): combination of formic acid and monolaurin in the diet of piglets infected by ETEC can become an alternative to antibiotics for reduction of the inflammatory process.

As an antimicrobial preparation, various authors also use benzoic acid. Ding (2017) assessed antibacterial properties of benzoic acid against Escherichia coli O157:H7 and determined that benzoic acid in combination with other substances can increase the safety and quality of fresh products.

Alborzi et al. (2018) also studied antimicrobial properties of different substances and determined the antimicrobial effect of benzoic acid and ethylenediaminetetraacetic acid. They assessed these substances as poten- 
tial antimicrobial preparations against bacteria Escherichia coli O157:H7 and Listeria innocua.

Because the solubility of benzoic acid in water equals $0.29 \mathrm{~g} / 100 \mathrm{~g}$ of water, the acid perhaps penetrates through the biological membranes of the eggs of nematodes in undissociated form, It is interesting that in our experiment, $0.1 \%$ benzoic acid caused no death to eggs of A. suum and T. suis.

Benzoic acid in the concentration of $0.5 \%(0.29 \%$ in it were in dissociated form in the solution, and $0.21 \mathrm{~g} / 100 \mathrm{~mL}$ of water were the weighed amount at the bottom of the test tube) killed around 5\% of eggs of $T$. suis and no eggs of A. suum. However, in $1 \%$ benzoic acid which contained 0.29 as solution and the rest as suspension at the bottom, death of the embryos occurred much more intensively: $20 \%$ eggs of $T$. suis and around $28 \%-A$. suum. This allows us to state that eggs are affected by both dissociated and undissociated acids (suspension of small undissolved particles of this substance)

According to the results of our previous studies on the influence of cinnamaldehyde and benzoic acid $\left(\mathrm{E}_{210}\right.$, Codex Alimentarius) on the vitality of invasive eggs of $A$. suum, the lowest $\mathrm{LC}_{50}$ parameters were observed for benzoic acid (Boyko \& Brygadyrenko, 2017). However, in a previous experiment we observed differences in the $\mathrm{LC}_{50}$ readings for cinnamaldehyde and benzoic acid: $0.2437 \%$ and $0.1240 \%$, respectively. Perhaps such results are associated with the use of eggs in the previous experiment at the development stage of 21-23 days, and in this experiment $-1-2$ days.

In our previous experiments, we studied also antiparasitic properties of these substances against nematode larvae $\mathrm{L}_{1-3}$ Strongyloides papillosus (Wedl, 1856) and $\mathrm{L}_{3}$ Haemonchus contortus (Rudolphi, 1803) (Boyko \& Brygadyrenko, 2019a, 2019b): notable nematocidal activity was displayed by cinnamaldehyde, benzoic acid and formic acid towards larvae of S. papillosus and H. contortus.

Similar experiments were conducted on eggs of $H$. contortus. Katiki et al. (2017) reported nematocidal properties of cinnamaldehyde. At the same time, the authors indicated antiparasitic effect of linalool against eggs of $H$. contortus. However, this substance had less notable anthelmintic effect. The results of our studies also showed notable anthelmintic effect of cinnamaldehyde against eggs of $A$. suum and $T$. suis. Our experiment with linalool did not show such impact on eggs of $A$. suum and $T$. suis, as on eggs of $H$. contortus in the study by Katiki et al. (2017). Around $90 \%$ of eggs of A. suum and T. suis had formed larvae in the end of the experiment after exposure to $3 \%$ emulsion of linalool.

Allowable daily consumption of benzoic acid for humans is $0.005 \mathrm{~g} / \mathrm{kg}$ (Zu et al., 2017), whereas $\mathrm{LD}_{50}$ of this substance for rats equals $1.7 \mathrm{~g} / \mathrm{kg}$ (Bedford \& Clarke, 1972; Jakimowska, 1961). According to the results of our experiments, to kill eggs of A. suum and T. suis during disinfection of the environmental objects in the housings of agricultural animals, $\mathrm{LD}_{50}$ equals 16.9 and $18.0 \mathrm{~g} / \mathrm{kg}$ respectively. $\mathrm{LD}_{50}$ of cinnamaldehyde for agricultural animals, particularly swine, was $1.16 \mathrm{~g} / \mathrm{kg}$. This parameter for rats was significantly higher accounting for $2.22 \mathrm{~g} / \mathrm{kg}$ (Jenner et al., 1964). In our experiment, the value for $A$. suum and $T$. suis was 16.2 and $5.7 \mathrm{~g} / \mathrm{kg}$ respectively. Thus, eggs of $A$. suum and $T$. suis were more resistant to cinnamaldehyde and benzoic acid than other organisms. Their $\mathrm{LD}_{50}$ values several times exceeded this parameter for other organisms.

\section{Conclusion}

One of the new spheres in agriculture is the study of anthelmintic properties of flavourings against nematodes of animals and humans. In practice, the food additives with antibacterial effect (cinnamaldehyde and benzoic acid) in intense pig farming could be used against eggs with nematodes of $A$. suum and T. suis, and also complexly take effect on pathogenic microorganisms in the housings of agricultural animals (after application to the litter, walls, places of watering, etc). These substances can stop the development of larvae in eggs of helminths and can be used in the future for obtaining preparations for disinfecting objects of the environment. At the same time, in pig farming complexes, use of cinnamaldehyde and benzoic acid would allow reduction in the use of synthetic substances against ascariasis and trichuriasis.

\section{References}

Alborzi, S., Bastarrachea, L. J., Ding, Q., \& Tikekar, R. V. (2018). Inactivation of Escherichia coli O157:H7 and Listeria innocua by benzoic acid, ethylenediaminetetraacetic acid and their combination in model wash water and simulated spinach washing. Journal of Food Science, 83(4), 1032-1040.

Bedford, P., \& Clarke, E. (1972). Experimental benzoic acid poisoning in the cat. Veterinary Record, 90(3), 53-58.

Boyko, A. A., \& Brygadyrenko, V. V. (2016). Influence of water infusion of medicinal plants on larvae of Strongyloides papillosus (Nematoda, Strongyloididae). Visnyk of Dnipropetrovsk University, Biology, Ecology, 24(2), 519-525.

Boyko, A. A., \& Brygadyrenko, V. V. (2017). Changes in the viability of the eggs of Ascaris suum under the influence of flavourings and source materials approved for use in and on foods. Biosystems Diversity, 25(2), 162-166.

Boyko, A. A., \& Brygadyrenko, V. V. (2018). The impact of certain flavourings and preservatives on the survivability of larvae of nematodes of Ruminantia. Regulatory Mechanisms in Biosystems, 9(1), 118-123.

Boyko, O. O., \& Brygadyrenko, V. V. (2019a). The impact of acids approved for use in foods on the vitality of Haemonchus contortus and Strongyloides papillosus (Nematoda) larvae. Helminthologia, 56(3), 202-210.

Boyko, O. O., \& Brygadyrenko, V. V. (2019b). The viability of Haemonchus contortus (Nematoda, Strongylida) and Strongyloides papillosus (Nematoda, Rhabditida) larvae exposed to various flavourings and source materials used in food production. Vestnik Zoologii, 53(6), 433-442.

Boyko, O. O., \& Brygadyrenko, V. V. (2019c). Nematocidial activity of aqueous solutions of plants of the families Cupressaceae, Rosaceae, Asteraceae, Fabaceae, Cannabaceae and Apiaceae. Biosystems Diversity, 27(3), 227-232.

Brütsch, T., Jaffuel, G., Vallat, A., Turlings, T.C.J., \& Chapuisat, M. (2017). Wood ants produce a potent antimicrobial agent by applying formic acid on treecollected resin. Ecology and Evolution, 7(7), 2249-2254.

Ceballos, L., Canton, C., Cadenazzi, G., Virkel, G., Dominguez, P., Moreno, L., Lanusse, C., \& Alvarez, L. (2019). Oxfendazole kinetics in pigs: In vivo assessment of its pattern of accumulation in Ascaris suum. Experimental Parasitology, 199, 52-58.

Cheng, S. S., Liu, J. Y., Huang, C. G., Hsui, Y. R., Chen, W. J., \& Chang, S. T. (2009). Insecticidal activities of leaf essential oils from Cinnamomum osmophloeum against three mosquito species. Bioresource Technology, 100(1), 457-464.

de Oliveira, N. T. E., Carvalho, P. L. de O., Genova, J. L., Silveira, F. H. R., Ogawa, L., Cristofori, E. C., Caxias Junior, O. A., \& Santana, A. L. A. (2019). Effect of endoparasites occurrence in sows from intensive production system. Revista Brasiliera de Parasitologia Veterinaria, 28(4), 722-727.

Ding, Q. (2017). The antimicrobial effect of benzoic acid or propyl paraben treatment combined with UV-A light on Escherichia coli O157:H7. University of Maryland, College Park, Maryland.

Durgadevi, R., Veera Ravi, A., Alexpandi, R., Krishnan Swetha, T., Abirami, G., Vishnu, S., \& Karutha Pandian, S. (2019). Virulence targeted inhibitory effect of linalool against the exclusive uropathogen Proteus mirabilis. Biofouling, $35(5), 508-525$

Fitri Noor Inaya, A., Kismiyati, K., \& Subekti, S. (2019). Pengaruh perasan biji pepaya (Carica papaya) terhadap kerusakan telur Argulus japonicus [The influence of papaya seed (Carica papaya) toward the damage eggs of Argulus japonicus]. Jumal Ilmiah Perikanan Dan Kelautan, 7(2), 159.

Jakimowska, K. (1961). Pharmacological properties of certain aromatic boron compounds. Acta Physiologica Polonica, 12, 173-182.

Jakobsen, S. R., Myhill, L. J., \& Williams, A. R. (2019). Effects of Ascaris and Trichuris antigens on cytokine production in porcine blood mononuclear and epithelial cells. Veterinary Immunology and Immunopathology, 211, 6-9.

Jenner, P. M., Hagan, E. C., Taylor, J. M., Cook, E. L., \& Fitzhugh, O. G. (1964). Food flavourings and compounds of related structure I. Acute oral toxicity. Food and Cosmetics Toxicology, 2, 327-343.

Katiki, L. M., Barbieri, A. M. E., Araujo, R. C., Veríssimo, C. J., Louvandini, H., \& Ferreira, J. F. S. (2017). Synergistic interaction of ten essential oils against Haemonchus contortus in vitro. Veterinary Parasitology, 243, 47-51.

Lee, E. J., Kim, J. R., Choi, D. R., \& Ahn, Y. J. (2008). Toxicity of cassia and cinnamon oil compounds and cinnamaldehyde-related compounds to Sitophilus oryzae (Coleoptera: Curculionidae). Journal of Econonic Entomology, 101(6), 1960-1966.

Lindgren, K., Gunnarsson, S., Höglund, J., Lindahl, C., \& Roepstorff, A. (2019). Nematode parasite eggs in pasture soils and pigs on organic farms in Sweden. Organic Agriculture, 2020, in press.

Manu, D. K. (2016). Antimicrobial activity of cinnamaldehyde or geraniol alone or combined with high pressure processing to destroy Escherichia coli O157:H7 and Salmonella enterica in juices. Iowa State University, Ames.

Montgomery, J. (2000). Groundwater chemicals desk reference. 3rd edition. Imprint CRC Press, Boca Raton.

Na, Y. E., Kim, S. I., Bang, H. S., Kim, B. S., \& Ahn, Y. J. (2011). Fumigant toxicity of cassia and cinnamon oils and cinnamaldehyde and structurally related com- 
pounds to Dermanyssus gallinae (Acari: Dermanyssidae). Veterinary Parasitology, 178, 324-329.

Nwafor, I. C., Roberts, H., \& Fourie, P. (2019). Prevalence of gastrointestinal helminths and parasites in smallholder pigs reared in the central free state province. Onderstepoort Journal of Veterinary Research, 86(1), e1-e8.

Nyasinge, J., Montero, G. D., Valladares, M. B., Noah, J. O. O., \& Nkwangu, D. (2018). In-vitro antihelminthic activity of alcoholic extract from Paullinia pinnata Linn against Ascaris suum. Revista Cubana de Plantas Medicinales, 23(1), 443.

Oh, K.-S., Kim, G.-T., Ahn, K.-S., \& Shin, S.-S. (2016). Effects of disinfectants on larval development of Ascaris suum eggs. Korean Journal of Parasitology, 54(1), 103-107.

Palchykov, V. A., Zazharskyi, V. V., Brygadyrenko, V. V., Davydenko, P. O., Kulishenko, O. M., Borovik, I. V., Chumak, V., Kryvaya, A., \& Boyko, O. O. (2019). Bactericidal, protistocidal, nematodicidal properties and chemical composition of ethanol extract of Punica granatum peel. Biosystems Diversity, 27(3), 300-306.

Palma, A., Matamoros, G., Escobar, D., Sánchez, A. L., \& Fontecha, G. (2020). Absence of mutations associated with resistance to benzimidazole in the betatubulin gene of Ascaris sum. Revista da Sociedade Brasiliera de Medicina Tropical, 53, e20190155.

Ren, C., Wang, Y., Lin, X., Song, H., Zhou, Q., Xu, W., Shi, K., Chen, J., Song, J., Chen, F., Zhang, S., \& Guan, W. (2020). A combination of formic acid and monolaurin attenuates enterotoxigenic Escherichia coli induced intestinal inflammation in piglets by inhibiting the NF-B/MAPK pathways with modulation of gut microbiota. Journal of Agricultural and Food Chemistry, 68(14), 4155-4165.

Saddiq, A. A., \& Khayyat, S. A. (2010). Chemical and antimicrobial studies of monoterpene: Citral. Pesticide Biochemistry and Physiology, 98(1), 89-93.

Sea, O., Hariadi, M., Koesdarto, S., Yunus, M., Kusnoto, K., \& Ngakan Made, R. W. (2017). Anthelmintic activity of basil leaves (Ocimum sanctum Linn.) infusion against Ascaris suum in vitro. Journal of Parasite Science, 1(2), 47-50.

Shen, F., Xing, M., Liu, L., Tang, X., Wang, W., Wang, X., Wu, X., Wang, X., Wang, X., Wang, G., Zhang, J., Li, L., Zhang, J., \& Yu, L. (2012). Efficacy of trans-cinnamaldehyde against Psoroptes cuniculi in vitro. Parasitology Research, 110, 1321-1326.
Simalango, D. M., \& Utami, N. V. (2014). In-vitro antihelminthic effect of ethanol extract of black seeds (Nigella sativa) against Ascaris suum. Procedia Chemistry, 13, 181-185.

Ullah, I., Latif, A. K., Ali, L., Khan, A. R., Waqas, M., Hussain, J., Lee, I. J., \& Shin, J.H. (2015). Benzaldehyde as an insecticidal, antimicrobial, and antioxidant compound produced by Photorhabdus temperata M1021. Journal of Microbiology, 53(2), 127-133.

Vandekerckhove, E., Vlaminck, J., Sacristán, R. del P., \& Geldhof, P. (2019). Effect of strategic deworming on Ascaris sum exposure and technical performance parameters in fattening pigs. Veterinary Parasitology, 268, 67-72.

Von Oettingen, W. F. (1960). The aliphatic acids and their esters: Toxicity and potential dangers. The saturated monobasic aliphatic acids and their esters. American Medical Association Archives of Industrial Health, 21(1), 28-65.

Williams, A. R., Peña-Espinoza, M. A., Boas, U., Simonsen, H. T., Enemark, H. L., \& Thamsborg, S. M. (2016). Anthelmintic activity of chicory (Cichorium intybus): In vitro effects on swine nematodes and relationship to sesquiterpene lactone composition. Parasitology, 143(6), 770-777.

Williams, A. R., Soelberg, J., \& Jäger, A. K. (2016). Anthelmintic properties of traditional African and Caribbean medicinal plants: Identification of extracts with potent activity against Ascaris suum in vitro. Parasite, 23, 24.

Yi, C. G., Hieu, T. T., Lee, S. H., Choi, B. R., Kwond, M., \& Ahna, Y. J. (2016). Toxicity of Lavandula angustifolia oil constituents and spray formulations to insecticide-susceptible and pyrethroid-resistant Plutella xylostella and its endoparasitoid Cotesia glomerata. Pest Management Science, 72(6), 1202-1210.

Zajac, A. M., \& Conboy, G. A. (Eds.). (2011). Veterinary clinical parasitology. $8^{\text {th }}$ ed. John Wiley and Sons, London.

Zhao, J., Han, Q., Liao, C., Wang, J., Wu, L., Liu, Q., \& Lindsay, D. S. (2017). Effects of in vivo and in vitro treatment of Ascaris suum eggs with anthelmintic agents on embryonation and infectivity for mice. Joumal of Parasitology, 103(5), 598-601.

Zheng, Y., Xie, Y., Geldhof, P., Vlaminck, J., Ma, G., Gasser, R. B., \& Wang, T. (2020). High anti-Ascaris seroprevalence in fattening pigs in Sichuan, China, calls for improved management strategies. Parasites Vectors, 13(1), 60.

Zu, K., Pizzurro, D. M., Lewandowski, T. A., \& Goodman, J. E. (2017). Pharmacokinetic data reduce uncertainty in the acceptable daily intake for benzoic acid and its salts. Regulatory Toxicology and Pharmacology, 89, 83-94. 